$$
\begin{array}{r|l}
\text { Jurnal Sains Komputer dan Teknologi Informasi } & \text { Page } \\
\text { e-issn: 2655-7460. Volume i No.2, Mei 2019 } & \text { 6-9 }
\end{array}
$$

\title{
RANCANG BANGUN PERMAINAN MISI PANGLIMA BATUR MENGGUNAKAN ENGINE SCIRRA CONSTRUCT 2
}

\author{
${ }^{1}$ Mochammad Ichsan, ${ }^{2} \mathrm{M}$. Haris Qamaruzzaman \\ ${ }^{1}$ Manajemen Informatika - STMIK Palangkaraya, ${ }^{2}$ Ilmu Komputer - Universitas Muhammadiyah \\ Palangkaraya \\ ${ }^{1}$ Jl. G.Obos No. 114 Palangkaraya, ${ }^{2}$ Jl. RTA. Milono Km. 1,5 Palangkaraya, Kalimantan Tengah \\ E-mail : 'salafi_ichsan@yahoo.co.id, ${ }^{2}$ harisqamaruzzaman@yahoo.co.id
}

\begin{abstract}
ABSTRAK
Banyak game bermunculan yang dikembangkan oleh perorangan ataupun organisasi, dengan adanya sosial media facebook game didalamnya juga berhasil membius para pecinta game mulai dari anak-anak hingga orang dewasa.Permasalahan dari penelitian ini adalah bagaimana membuat sebuah game facebook dengan menggunakan tokoh Panglima Batur sebagai karakter utamanya yang bertujuan untuk mengangkat nama tokoh dari Panglima Batur itu sendiri. Game ini merupakan game berbasis web yang dibuat menggunakan game engine Scirra Construct 2. Metode yang digunakan dalam penelitian ini menggunakan pengembangan multimedia yang terdiri dari 6 tahapan yaitu concept, design, material collecting dan assembly. Hasil penelitian ini adalah sebuah Game Facebook bertipe adventure dengan mengangkat tokoh Panglima Batur sebagai karakter utama nya dan dikombinasikan dengan musik latar serta karakter musuh pada setiap stage. Game ini dapat menjadi sarana untuk mengangkat budaya dalam bentuk visual game.
\end{abstract}

Kata kunci : Game Adventure, Scirra Construct 2, Panglima Batur

\begin{abstract}
Many emerging games developed by individual or organization, with social media Facebook games in it also successfully whising the lovers of games from children to adults. The problem of this research is how to make a Facebook game using the character of Panglima Batur as the main character that aims to raise the name of the character from Commander Batur itself. This game is a Web-based game created using Scirra Construct 2 engine game. The method used in this study uses multimedia development consisting of 6 stages, namely concept, design, material collecting and assembly. The result of this research is a Facebook adventure Game by raising the character of Panglima Batur as its main character and combined with background music and enemy characters at each stage. This game can be a means to lift cultures in the form of game visuals.
\end{abstract}

Keywords: Adventure games, Scirra Construct 2, Commander Batur

\section{Pendahuluan}

Melihat dari perkembangan teknologi game di dunia maya khususnya, sampai saat ini menampilkan berbagai jenis ide dan karya baru. Banyak game bermunculan yang dikembangkan oleh perorangan ataupun organisasi, dengan adanya social media facebook game didalamnya juga berhasil membius para pecinta game mulai dari anak-anak hingga orang dewasa. Kemudian banyak game-game baru berbasis flash seperti halnya game yang bernama Angry Bird, pecinta game ini beragam mulai dari anak-anak hingga dewasa. Dari kasus tersebut sampai saat ini telah banyak dikembangkan perangkat lunak yang dapat membuat game dengan tapilan seperti flash dengan basis lain yaitu HTML5.

HTML 5 adalah revisi kelima dari HTML yang telah dikembangkan untuk memperbaiki teknologi pada HTML agar mendukung teknologi multimedia dan grafis pada web browser tanpa tergantung pada jenis browser tertentu. Dengan teknologi HTML 5 yang bisa dipadukan dengan menggunakan CSS3 dan 
Javascript, banyak yang mulai mengembangkan sebuah game yang tujuannya adalah player tidak perlu lagi memasang tambahan plugin untuk memainkan game. Pada dasarnya game yang di buat dengan teknologi HTML 5 ini akan berjalan di web browser. Namun game yang dibuat dengan HTML 5 ini bisa juga di mainkan secara multi platform dengan di build terlebih dahulu menggunakan Scirra Construct 2.

Scirra Construct 2 adalah sebuah games engine yang digunakan untuk membuat games berbasis HTML 5 sekaligus bisa juga membuatnya ke dalam beberapa platform. Dengan menggunakan Scirra Construct 2, games yang telah di buat bisa di build juga ke platform seperti Web Browser, Desktop, dan Mobile.

Game ini menceritakan tentang perjalanan dari seorang Panglima Batur melewati musuhmusuh dan rintangan untuk menuju ke bendera Indonesia.

\section{Kajian Teori}

\subsection{Rancang Bangun}

Menurut R. Presman (2010), rancang adalah proses menganalisa kebutuhan dan mendiskripsikan dengan detail komponenkomponen yang akan di inplementasi. Dalam buku tersebut juga dijelaskan pengertian dari bangun yaitu menciptakan sistem baru atau memperbaiki sistem yang sudah ada

\subsection{Game}

Menurut Adams, Ernest (2010:2), Game adalah salah satu jenis aktifitas bermain, yangdidalamnya dilakukan dalam konteks berpura - pura namun terlihat seperti realitas, yang mana pemainnya memiliki tujuan untuk mendapatkan satu kemenangan serta dilakukan dengan sesuai dengan aturan permainan yang dibuat.

\section{Metode Penelitian}

Penelitian ini menggunakan metode pengembangan multimedia dengan tahapan sebagai berikut :

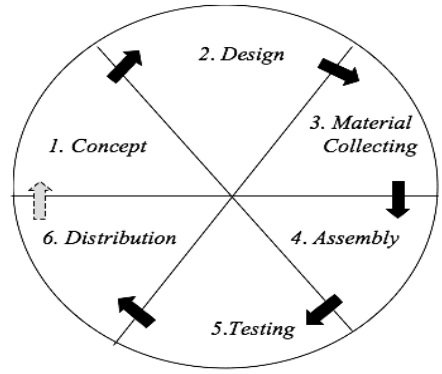

Gambar 1. Metode Pengembangan Multimedia (Sumber: Sutopo, 2003)

\section{Perancangan Sistem}

\subsection{Konsep (Concept)}

Game ini berjenis adventure yang menceritakan petualangan burung Tingang. Latar yang diambil dalam game berupa nuansa hutan. Dalam game ini panglima batur harus menghindari beberapa karakter penghalang dan melewati rintangan yang ada untuk mencapai finish. Game ini dengan sistem single player dan dibangun dengan grafis 2D (dua dimensi).

\subsection{Perancangan (Design)}

Pada tahap desain ini dilakukan perancangan objek, storyboard, struktur menu dan arsitektur mengenai game yang akan dibangun. Objek yang terdiri dari karakter, item, rintangan (obstacle) dan lingkungan (environment) digambar menggunakan software Corel Draw X7.

Tabel 1. Storyboard Stage 1

\begin{tabular}{|l|l|}
\hline & $\begin{array}{l}\text { Menu Utama pada game } \\
\text { ini, dimana ada beberapa } \\
\text { pilihan menu yaitu: Play } \\
\text { Now dan About. }\end{array}$ \\
\hline & $\begin{array}{l}\text { Halaman Permainan } \\
\text { stage 1, Panglima } \\
\text { Batur harus } \\
\text { melewati tentara } \\
\text { belanda dan jebakan } \\
\text { lainnya. }\end{array}$ \\
\hline & $\begin{array}{l}\text { Tampilan Jika Pemain } \\
\text { gagal, maka akan } \\
\text { muncul layar game } \\
\text { over, dimana terdapat } \\
\text { tombol Try Again jika } \\
\text { pemain ingin mengulangi } \\
\text { permainan. }\end{array}$ \\
\hline & $\begin{array}{l}\text { Tampilan Pemain } \\
\text { jika pemain berhasil } \\
\text { mencapai bendera maka } \\
\text { akan langsung lanjut ke } \\
\text { stage 2. }\end{array}$ \\
\hline
\end{tabular}




$$
\begin{array}{r|l}
\text { Jurnal Sains Komputer dan Teknologi Informasi } & \text { Page } \\
\text { e-issn: 2655-7460. Volume i No.2, Mei 2019 } & \text { 6-9 }
\end{array}
$$

Storyboard stage 1 ini, misinya adalah pemain membawa Panglima Batur untuk melewati musuh dan halang rintang lainnya agar dapat sampai ke bendera. Jika stage 1 ini terselesaikan maka secara otomatis lanjut stage 2 .

Tabel 2. Storyboard Stage 2

\begin{tabular}{|l|l}
\hline & $\begin{array}{l}\text { Halaman } \\
\text { Permainan stage } \\
\text { 2, Panglima Batur } \\
\text { harus melewati } \\
\text { tentara belanda } \\
\text { dan jebakan } \\
\text { lainnya. }\end{array}$ \\
\hline & \begin{tabular}{l} 
Tampilan \\
Pemain jika \\
pemain berhasil \\
mencapai bendera \\
maka akan \\
\hline
\end{tabular} \\
\hline
\end{tabular}

Storyboard stage 2 ini, misinya adalah pemain membawa Panglima Batur untuk melewati musuh dan halang rintang lainnya agar dapat sampai ke bendera. Jika stage 2 ini terselesaikan maka secara otomatis lanjut stage 3 .

4.3 Pengumpulan Material (Material Collecting) Pada tahap pengumpulan materi, seluruh bahan yang dibutuhkan akan dikumpulkan seperti image, audio, animasi dan lain-lain. Pengumpulan bahan ini dimaksudkan untuk mencari contoh ynag tepat tentang bentuk dan kondisi lingkungan berlatarkan nuansa satwa langka orang utan. Bahan tersebut dikumpulkan dalam bentuk objek-objek yang telah dibuat pada tahap desain dan file audio yang nantinya akan digunakan dalam game seperti suara latar audio. Seluruh bahan yang dikumplkan tersebut yang berkaitan dengan satwa langka.

4.4 TahapPembuatan Game (Assembly)

Pada tahap ini adalah tahap pembuatan semua objek multimedia berdasarkan perancangan yang telah dibuat. Objek 2D berupa karakter player dan objek-objek lainnya seperti item, karakter musuh dan lain-lainnya dibuat menggunakan software Corel Draw X7.

\section{Implementasi dan Pembahasan}

Tahap ini merupakan tahap yang berisi penjelasan tentang manual antar muka sistem. Antar muka pengguna pada game ini terdiri dari

Tampilan menu utama memuat tombol Play Now, How to Play dan About, sebagaimana gambar 2 berikut :

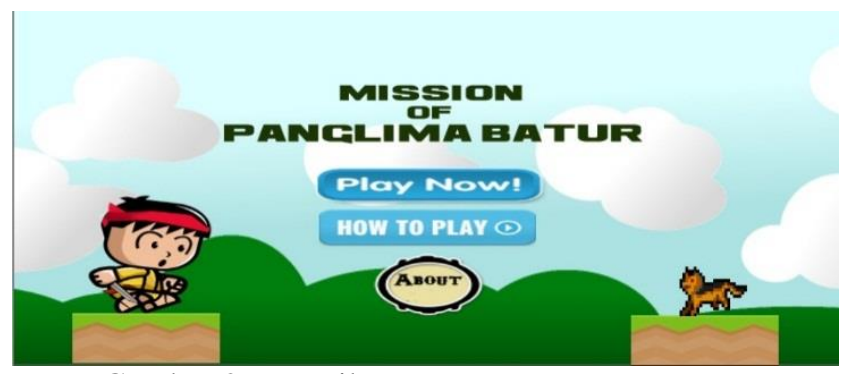

Gambar 2. Tampilan Menu Utama

Pilihan tombol Play Now untuk memulai permainan, tombol About informasi tentang Panglima Batur dan pembuat game dan tombol How to Play untuk informasi tentang cara memainkan game.

Saat tombol Play Now diklik, maka akan masuk pada game stage 1 dan pemain harus menyelesaikannya untuk bisa lanjut ke stage berikutnya seperti terlihat pada gambar 3 :

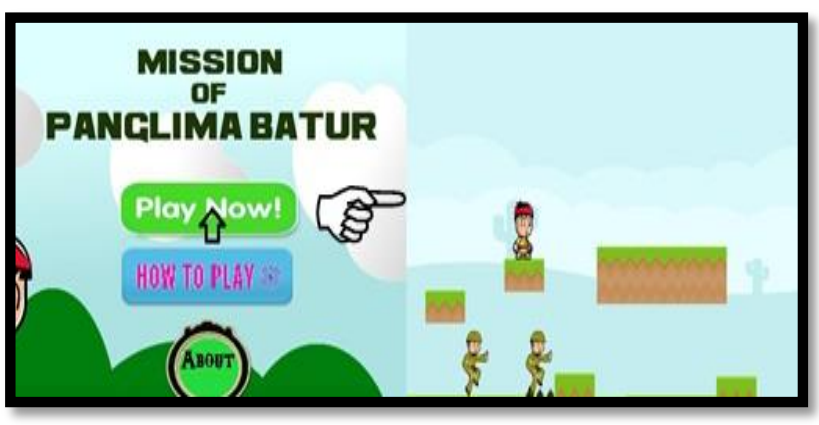

Gambar 3. Tampilan pada saat permainan di mulai

Jika pemain gagal maka pemain akan masuk pada tampilan Game Over dimana pada tampilan ini terdapat tombol Retry untuk mengulangi permainan. 


\section{Kesimpulan}

Penelitian ini telah menghasilkan sebuah game berbasis web yaitu Misi Panglima Batur dengan menggunakan game engine Scirra Construct 2 dengan menerapkan metode pengembangan Multimedia dan game ini sudah dipublikasikan kedalam facebook yang bertujuan mengenalkan tentang seorang panglima batur yang merupakan pejuang dari Kalimantan Tengah.

\section{Daftar Pustaka}

Adams, E. 2010. Fundamentals of Game Design Second Edition. New Rider Games: Berkeley.

Haris, Ferdiyani. 2018. Rancang Bangun Aplikasi Ensiklopedia Berbasis Android. Jurnal Sains Komputer dan Teknologi Informasi. Vol 1 Issue 1 e-ISSN 2655-7460. https://doi.org/10.33084/jsakti.v1i1.448

Hartono, D. A. 2014. Perancangan Game Multiplatform Menggunakan Scirra Construct 2 dan HTML 5, AMIKOM, Yogyakarta.

Junitasari, D. S. 2013. Perancangan dan Pembuatan Game Diponegoro Adventure sebagai Media Pembalajaran IPS Menggunakan Engine Scrirra Construct 2, AMIKOM, Yogyakarta.

Jogiyanto, HM. 2005. Analisis dan Desain. Penerbit Andi, Yogyakarta.

Novak, Jeannie. 2012. Game Development Essentials Third Edition. Canada: Delmar, Cengage Learning..

Qamaruzzaman, M. H. 2018. Sistem Informasi Berbasis Mobile Benda-Benda Tradisional Pada Museum Balanga Palangkaraya. Jurnal Sains Komputer dan Teknologi Informasi. Vol 1 Issue 1 e-ISSN 2655-7460. https://doi.org/10.33084/jsakti.v1i1.455

R. Pressman. 2010. Software Engineering A Practitione's Aproach 7th. United States : Mc. Graw Hill.

Sutopo, Ariesto Hadi. 2003. Multimedia Interaktif dengan Flash. Graha Ilmu, Yogyakarta.

Whitten JL, Bentley LD, Dittman KC. 2004. System Analysis and Design Methods. Diterjemahkan oleh : Tim Penerjemah Andi. Yogyakarta. 